\title{
Alimentar a la persona enferma: un imperativo ético y un derecho humano
}

\author{
Feeding the ill person: an ethical imperative and a human right
}

Alimentando os doentes: um imperativo ético e um direito humano

\author{
Diana Cárdenas, MD, $\mathrm{PhD}^{1}$
}

https://doi.org/10.35454/rncm.v4supl1.341

Este número temático sobre bioética y derechos humanos en nutrición clínica surge de la necesidad de discutir acerca de las problemáticas y cuestionamientos éticos que surgen cuando se alimenta a la persona enferma. Alimentar a la persona enferma, objeto central de la disciplina de la nutrición clínica, implica una responsabilidad que debe ejercerse de acuerdo con principios y valores.

El desarrollo tecnológico y situaciones difíciles y extremas como el paciente en estado vegetativo persistente, el paciente con demencia, en cuidados intensivos, en cuidados paliativos o al final de vida requieren de manos expertas para brindar los alimentos que se ajusten a sus necesidades particulares. Frente a estas situaciones nos preguntamos qué principios y valores fundamentan la práctica de la nutrición clínica. La hipótesis que se plantea es que, al cuestionar la dimensión ética del cuidado nutricional, se están cuestionando los valores del "cuidado" y de la medicina de forma más amplia. Mi propuesta después de un trabajo de investigación y de reflexión de varios años, el cual este número de la revista intenta plasmar, es que, al afirmarse como un objeto de la ética, la nutrición clínica puede presentarse legítimamente como un cuidado en la práctica médica.

El término "cuidado" puede tener distintos sentidos. Según Frederic Worms, este término (care en inglés, soins en francés) hace referencia a "toda práctica que se inclina a atender a un ser vivo en sus necesidades materiales o sus sufrimientos vitales, y esto por consideración hacia ese mismo ser"(1). Esta definición implica dos elementos indisociables: primero, se "cuida" a un ser que sufre de

dianacardenasbraz@gmail.com "algo", una necesidad o un sufrimiento identificable y que se puede tratar (cuidado terapéutico). En el caso de la nutrición clínica se trata de atender una necesidad vital de nutrientes a la cual es posible responder con la terapia médica nutricional, en especial la nutrición artificial. Y segundo, se "cuida" o trata a "alguien", lo que comporta una dimensión intencional y relacional (cuidado relacional).

La nutrición clínica implica la interacción del profesional de salud con el paciente, en la que el experto en nutrición determina un diagnóstico del estado nutricional y una consecuente indicación de terapia nutricional, ante la cual el consentimiento del paciente o del cuidador es primordial. Para lograr un consentimiento pleno del paciente, el profesional de la salud debe brindar la información completa y, así mismo, conocer las preferencias y los deseos del paciente, ya sea si se alimenta de manera natural o artificial. La administración de una terapia nutricional a través de una vía artificial no debe modificar el sentido de "alimentar". Al pasar de una alimentación oral a una nutrición administrada artificialmente, se pasa de un acto puramente de cuidado (es decir, cubrir una necesidad vital) a un acto terapéutico que necesita de una indicación médica, y unos objetivos terapéuticos, con los consecuentes posibles riesgos y beneficios. Esto demuestra la dimensión relacional del cuidado en esta disciplina. De esta forma, la práctica de la nutrición clínica puede constituirse como una manifestación de la consideración por el otro que implica ir más allá de la dimensión puramente biológica e incluir el aspecto simbólico y afectivo que conlleva el acto de alimentarse ${ }^{(2)}$. Por tanto, alimentar a la persona enferma por vía natural o artificial debe ser considerado como un verdadero cuidado en su dimensión ética y un aspecto central de la práctica clínica. 
Los profesionales de la salud tienen la responsabilidad y el compromiso de preocuparse por la alimentación de cada persona enferma. Esta preocupación necesita de una cierta atención sobre la problemática de desnutrición que puede comprometer el pronóstico del paciente. El paciente en riesgo o en estado de desnutrición debe ser considerado como una persona doblemente vulnerable ${ }^{(2)}$. Por un lado, su integridad está comprometida y es frágil por su relación de dependencia que implica la necesidad de manos expertas para cubrir sus necesidades en nutrientes. Por otro lado, la desnutrición es un problema casi invisible ante la medicina actual. Los médicos no están preparados ${ }^{(3,4)}$ ni sensibilizados con esta problemática, y la definición y los criterios diagnósticos (aunque parecen haber logrado un consenso internacional con los criterios de Liderazgo Global sobre Desnutrición [GLIM]) aún son objeto de debate en la comunidad científica $^{(5)}$. Así las cosas, es importante reconocer que el sentido ético más profundo de vulnerabilidad implica el compromiso de responsabilidad, consideración y preocupación por los demás. De esta forma, reconocer al paciente desnutrido como vulnerable implica la responsabilidad de alimentarlo.

Además, la responsabilidad ética de alimentar a la persona enferma incluye reconocer el valor individual de cada ser; es decir, su dignidad, entendida como un principio ligado a un valor intrínseco y absoluto, más allá de cualquier precio, que solo posee el ser humano ${ }^{(6)}$. La dignidad es el valor fundamental de los derechos humanos, lo cual lleva a cuestionarse el lugar que ocupa la nutrición en la preservación de la dignidad humana y la defensa de los derechos humanos. Por tanto, reconocer que el acceso al cuidado nutricional es un derecho humano y darle todo el sentido tanto político, clínico y ético es reconocer un gran avance para la nutrición clínica ${ }^{(7)}$. Sin embargo, surge una nueva pregunta: ¿cómo este derecho puede influir en las decisiones clínicas? De lo que se trata es de entender el significado de la terapia médica nutricional, más precisamente, de considerar, además del efecto médico-biológico, las razones para alimentar a un paciente con riesgo o en estado de desnutrición. En definitiva, el reto de este cuestionamiento es evaluar el lugar que ocupa la nutrición en la preservación de la dignidad humana.

En conclusión, la práctica de la nutrición clínica a través del cuidado nutricional debe ser considerada como una expresión de humanidad. Los interrogantes arriba mencionados inspiran un cuestionamiento desde la ética y, en particular, desde la ética del cuidado, que permiten afirmar, como lo hace la filósofa francesa Corine Pelluchon en su obra Les Nourritures: "La ética no es solo la dimensión de mi relación con los demás; también depende de mi relación con los alimentos" ${ }^{(8)}$. Es decir, más allá de considerar el punto de partida de la ética en la relación con el otro ${ }^{(9)}$, es posible que mi relación con los alimentos sea el lugar original de la ética ${ }^{(8)}$.

Quiero agradecer en nombre de todo el equipo editorial de la Revista a Lina María Sierra Tobón, nutricionista, especialista en Nutrición Clínica y magíster en Bioética, por su gran trabajo en la preparación y edición de este número. Coincidimos en varios aspectos como en una visión de la ética centrada en el valor del cuidado, la exigencia en el trabajo y el gusto por lo que hacemos. ¡Gracias, Lina!

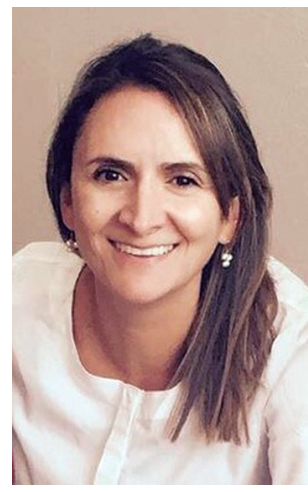

Diana Cárdenas, MD, PhD Editora de la Revista de Nutrición Clínica y Metabolismo (ACNC). Profesora e investigadora del Instituto de Nutrición, Genética y Metabolismo, Facultad de Medicina, Universidad El Bosque. Bogotá, Colombia.

\section{Referencias bibliográficas}

1. Worms F. Les deux concepts du soin. En: Worms F (editor). Le moment du soin, à quoi tenons-nous? París: Presses Universitaires de France; 2010. p. 17-36.

2. Cardenas D. Nutrition en Médecine: approche èpistemologique, problèmes éthiques et cas cliniques. París: L'Harmattan; 2020.

3. Crowley J, Ball L, Hiddink GJ. Nutrition in medical education: a systematic review. Lancet Planet Health. 2019;3(9):e379-e389. doi: 10.1016/S2542-5196(19)30171-8.

4. Cardenas D, Díaz G, Cadavid J, Lipovestky F, Canicoba M, Sánchez $\mathrm{P}$, et al. Nutrition in medical education in Latin America: Results of a cross-sectional survey. JPEN J Parenter Enteral Nutr. 2021. doi: 10.1002/jpen.2107.

5. Cardenas D, Deutz NEP. Is the definition of malnutrition a Sisyphean task? Clin Nutr ESPEN. 2019;29:246-247. doi: 10.1016/j.clnesp.2018.10.005.

6. Kant E. Fondements de la Métaphysique des mœurs. Traduction et notes de Victor Delbos. París: Delagrave; 1957.

7. Cardenas D, Correia MITD, Ochoa JB, Hardy G, RodriguezVentimilla D, Bermúdez CE, Papapietro K, Hankard R, Briend A, Ungpinitpong W, Zakka KM, Pounds T, Cuerda C, Barazzoni R. Clinical Nutrition and Human Rights. An International Position Paper. Nutr Clin Pract. 2021 Jun;36(3):534-544. doi: 10.1002/ncp.10667.

8. Pelluchon C. Les nourritures. Philosophie du corps politique. París: Seuil; 2015.

9. Levinas E. Autrement qu'être, ou, Au-delà de l'essence. La Haya: Martinus Nijhoff; 1974. 